The balance is made by the Chicago Laboratory Supply and Scale Company, 31-45 West Randolph Street, and will be known as the "Chaslyn Balance."

\title{
THE DETERTINATION OF POTASH AS PERCHLORATE.
}

\section{BY F. S. SHIVER.}

Received July r4, 1808 .

$\int \begin{gathered}\mathrm{HE} \text { increasing use of potash salts for fertilizing purposes } \\ \text { has made the determination of potash a question of prime }\end{gathered}$ importance to the agricultural chemist.

The desire to devise a method at the same time rapid and accurate has been manifested in many ways in the past few years, especially in Germany, the seat of the great potash deposits.

The German chemists believe they have solved the problem in the so-called Stassfurt method, which as all know permits of the separation of the potash by platinum chloride after previous precipitation of sulphuric acid by barium chloride in slight excess, and in a strongly acid solution. This method with practice is quite accurate and rapid, with a slight tendency, however, to high results in my hands. It possesses little ad. vantage over the Lindo-Gladding method, in so far as rapidity and accuracy are concerned.

The following determinations were made by the Stassfurt method-potassium sulphate, C. P., and potassium chloride, C. P., were mixed with such impurities as to imitate the composition of commercial sulphate of potash, sulphate of potash and magnesia, kainit, and muriate.

\section{TABLE I.}

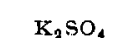
used. Gram.

Sulphate of potash ........... 0.3284

Sulphate of potash and magnesia 0.1856

Kainit ................... 1000

\section{$\mathrm{Ke} 1$}

secd.

Muriate.................... 0.2506

0.2522
$\mathrm{K}_{2} \mathrm{SO}_{4}$ Gram.

$0.329 I$

0.3289

o. 1863

0.1870

o. 1003

o. 1009

$\mathrm{KCl}$

found.

Gram.

0.2498

0.2514

$$
\begin{aligned}
& \text { Errot on } \\
& \mathbf{K}_{\mathrm{SO}} \mathrm{SO}_{4} \text {. } \\
& \text { Gram. }
\end{aligned}
$$

Error on $\mathrm{K}_{2} \mathrm{O}$.

$+0.0007$

+0.0007
+0.0005
+0.0007

+0.0007
+0.0014

$+0.0003$

$+0.0009$

Error on

KCl.

Gram.

$-0.0008$

$-0.0008$ Gram.

$+0.0004$

+0.0003
+0.0004

$+0.0008$

$+0.0002$

$+0.0005$

Error on $\mathrm{K}_{2} \mathrm{O}$.

$-0.0005$

$-0.0005$

The factor used for converting potassium platinichloride into potassium sulphate was 0.35694 which is practically the same 
as that recommended in the Stassfurt method; viz., 0.357 . The factor used for converting potassium platinichloride into potassium chloride was 0.30557 which is practically the same as that recommended in the Stassfurt method; viz., 0.3056 . It will be seen from the above results that the method is quite accurate with a tendency, however, to slightly high results.

In view of the increasing importance of the potash determination, it is highly desirable that we should possess a check method, rapid and accurate, based on some other principle of separation than that with platinum chloride.

All of our present methods for the determination of potash, involve the use of platinum chloride as a means of final separation, and hence they are all subject to the same general sources of error, such as solubility of the platinichloride in the eighty per cent. wash alcohol used, etc.

Of all the salts which potassium forms with acids, none are as well adapted for furnishing the basis of another process as the perchlorate, which is nearly insoluble in strong alcohol.

As all the compounds which perchloric acid forms with the bases other than potash and ammonia are soluble in alcohol, we may readily deduce the basis of another process. The determination of potash as perchlorate, is an old process due to Sérullas who first noticed the insolubility of the salt in alcohol, and to Schloesing who made it the basis of a new process. Schloesing's process, improved later by Kraut has, however, not come generally into use since the same produces inaccurate results.

W. Wense has made the process usefulsince he diminishes the solvent action of the alcohol on the perchlorate through the addition of slight quantities of perchloric acid. He describes the following course of procedure:

The solution to be investigated is evaporated, after once freeing it of sulphuric acid and non-volatile acids with perchloric acid in a porcelain dish. In order to wash the perchlorate easily it is desirable to produce the same in a granular condition. This is attained by warming the solution containing the potash on a water-bath before adding the perchloric acid, which must be run in drop by drop. In all cases there are used about one and a half to one and three-quarters times the amount of perchloric acid necessary for the decomposition of the salt present.

1 Ztschr. angew. Chem., $880 \mathrm{~s}, 69 \mathrm{r}$, and 2802,233 . 
After the addition of the perchloric acid the solution is evaporated, until all odor of hydrochloric acid or other volatile acids has disappeared. For washing the precipitate ninety-six per cent. alcohol is used, to which two-tenths per cent. of its weight in perchloric acid is added.

The residue from the evaporation is treated with ten cc. of the alcoholic wash solution, which may take up only $\frac{1}{20,000}$ of a part of potassium perchlorate, and the salt mass is then broken up with a stirrer.

Decantation is performed through a weighed filter, which has been previously dried at $120^{\circ}-130^{\circ} \mathrm{C}$, when the breaking up of the salt mass is repeated, and the residue again treated with the alcohol wash solution. The precipitate is then brought on the filter, and freed of the adhering perchloric acid solution by washing with a few cc. of pure alcohol. The filter is then pressed between folds of filter-paper, dried for twenty-five minutes at $\mathrm{I} 20^{\circ}-\mathrm{I} 30^{\circ} \mathrm{C}$, , and weighed.

One part of potassium perchlorate corresponds to 0.5382 part of potassium chloride, and 0.6289 part of potassium sulphate.

According to the author the whole washing with a good pump occupies only a short time, and requires fifty to seventy grams of alcohol. If the substance to be investigated contains sulphuric acid, the same is to be removed in the usual way by barium chloride previous to the determination of the potash. The author who used the method in the investigation of potassium chloride, C. P., commercial muriate, kainit, and carnallite obtained, according to the analyses reported, very favorable results.

R. Caspari ${ }^{1}$ recommends collecting the potassium perchlorate in tubes containing asbestos filters, and subsequent drying for twenty minutes at $\mathrm{I} 30^{\circ}-\mathrm{I} 50^{\circ} \mathrm{C}$. The tubes are allowed to cool in a desiccator, or in the air, and then weighed.

According to Caspari the method is applicable for fertilizers, ashes, and the like, in the presence of phosphoric acid, alkaline earths, iron, alumina and manganese, if the following method of procedure is adopted:

After the removal of sulphuric acid, the hydrochloric acid solution is evaporated for the purpose of getting rid of the free 1 Ztschr. angew. Chem., $1893,68$. 
acid, the residue stirred with twenty cc. of lot water after which perchloric acid is added in quanity not less than one and a half times that necessary for the decomposition of all salts present.

The solution is now evaporated with frequent stirring to a sirupy consistency, some hot water is again added, and the solution evaporated still again with occasional stirring until the disappearance of all odor of hydrochloric acid, and till the appearance of white fumes of perchloric acid. An evaporation of large quantities of perchloric acid is to be avoided. If this takes place, more perchloric acid is to be added.

The cooled, more or less sirupy, contents of the dish are well stirred up with about twenty cc. of wash alcohol (ninety-six per cent. alcohol containing two-tenths per cent. perchloric acid), taking care however not to reduce the potassium perchlorate to a fine powder. After the alcohclic solution has become clear, it is decanted through the asbestos filters, the washing repeated with the same quantity of wash alcohol, allowed to settle and decanted again.

The residue remaining in the dish is freed of alcohol by gently warming, evaporating again with about three-tenths gram of perchloric acid and a little water, and washing the cooled mass with several cc. of alcohol, with which it is also brought into the filters and the perchlorate in the tubes finally covered with a little pure alcohol. The potassium perchlorate obtained in this way contains, according to Caspari, no phosphoric acid, or only slight quantities of the same; on an average only 0.00057 gram phosphoric acid.

In the separation of sulphuric acid, Caspari seeks to avoid, as much as possible, a loss of potash, since he precipitates in a strong hydrochloric acid solution at the boiling temperature with a concentrated solution of barium chloride, made acid with hydrochloric acid. Experiments of the author prove also the applicability of the method in the presence of other acids not volatile on the water-bath, as chromic acid, and also boric, tartaric, and oxalic acids. If ammonium salts are present they are to be removed either with soda-lye or milk of lime, by gentle heating or through careful ignition. 
A. Kreider' has followed the method as described by Caspari, and has obtained very satisfactory results. Kreider found the Gooch crucible preferable in the filtering of the perchlorate and recommends the same instead of the tubes proposed by Caspari. In the presence of phosphoric acid, the previous separation of which is not necessary, it appeared advisable according to Kreider's experience to allow the perchlorate precipitate to stand with an excess of perchlorate acid before treating with alcohol.

Six determinations made of potassium unmixed with other bases or non-volatile acids gave the following results :

In two cases the theoretical amount of potash $\left(\mathrm{K}_{3} \mathrm{O}\right)$ was recovered as perchlorate; in three cases there was a loss of 0.0002 gram; and in one case a loss of 0.0003 gram, one-tenth gram of potassium chloride was operated on in all cases. In order to repeat Kreider's work, and to ascertain the accuracy of the process, the following work was undertaken. A solution of chemically pure potassium chloride was prepared by dissolving I.0005 grams in $200 \mathrm{cc}$. water. One cc. of the solution was found to contain 0.005 gram potassium chloride, aliquot portions being measured from a burette, evaporated, dried, and weighed.

In all the work here reported the method as proposed by Caspari with the use of the Gooch crucible, as suggested by Kreider, was employed.

However in the first three experiments reported the perchlorate was collected on paper filters as suggested by Wense, washed in the usual way, dried, and the perchlorate dissolved in hot water, and the solutions evaporated to dryness in platinum dishes and weighed.

In all cases the weighed perchlorate was a little discolored, due to the fact that the paper filters had been acted on to a slight extent by the perchloric acid, causing them to char a little around the edges during the process of drying. In the subsequent leaching with hot water, some of this carbonaceous material dissolved, and went in solution with the perchlorate.

The results obtained by weighing in dishes as above described were as follows:

1 Am.J. Sci., 49, 443. 
TABLEI.

\begin{tabular}{|c|c|c|c|c|}
\hline $\begin{array}{l}\mathrm{KCl} \\
\text { solution } \\
\text { used. } \\
\text { cc. }\end{array}$ & $\begin{array}{l}\text { Equiva- } \\
\text { lent to } \\
\text { KCl. } \\
\text { Gram. }\end{array}$ & $\begin{array}{l}\mathrm{KC1} \\
\text { found. } \\
\text { Gran. }\end{array}$ & $\begin{array}{c}\text { Errot on } \\
\text { KCl. } \\
\text { Gram. }\end{array}$ & $\begin{array}{c}\text { Error on } \\
\mathrm{K}_{2} \mathrm{O} . \\
\text { Gram. }\end{array}$ \\
\hline .. 6.2 & 0.0310 & 0.0310 & +0.0000 & +0.0000 \\
\hline .. 8.I & 0.0405 & $0.04 I I$ & +0.0006 & +0.0004 \\
\hline . 5.0 & $0.025^{\circ}$ & 0.0253 & +0.0003 & +0.0002 \\
\hline erage & 0.0322 & 0.0325 & +0.0003 & +0.0002 \\
\hline
\end{tabular}

It will thus be seen that the average error in these determinations is 0.0003 gram $\mathrm{KCl}$; it is possible that this slight plus error is due to the slight discoloration already noticed, and the weighing in dishes is not to be recommended though the results obtained are sufficiently accurate for all practical purposes. In the other experiments which follow the potassium chloride was weighed out directly for analysis, and the perchlorate was collected always in a Gooch crucible.

TABI.E II.

\begin{tabular}{|c|c|c|c|c|}
\hline & $\begin{array}{l}\text { KCl used. } \\
\text { Gram. }\end{array}$ & $\begin{array}{l}\mathrm{KCl} \text { found. } \\
\text { Gram. }\end{array}$ & $\begin{array}{l}\text { Errot on } \mathrm{KCl} \\
\text { Gran. }\end{array}$ & $\begin{array}{l}\text { Ertor on } \mathrm{K}_{2} \mathrm{O} \\
\text { Gram. }\end{array}$ \\
\hline $\mathrm{I} \ldots \ldots \ldots \ldots$ & 0.0848 & 0.0859 & $0.00 \mathrm{II}$ & +0.0007 \\
\hline$I I \ldots \ldots \ldots \ldots$ & 0.0217 & 0.0217 & 0.0000 & 0.0000 \\
\hline$I I I \ldots \ldots \ldots \ldots$ & 0.0419 & 0.0413 & -0.0006 & -0.0004 \\
\hline IV $\ldots \ldots \ldots \ldots$ & 0.1007 & 0.1009 & +0.0002 & $+0.000 r$ \\
\hline$V \ldots \ldots \ldots \ldots$ & 0.1003 & 0.1015 & +0.0012 & +0.0008 \\
\hline VI $\ldots \ldots \ldots \ldots$ & 0.1016 & O.IOI 5 & -0.0001 & -0.0000 \\
\hline VII $\ldots \ldots \ldots \ldots$ & 0.0217 & 0.0210 & -0.0007 & -0.0004 \\
\hline Average.. & 0.0675 & 0.0677 & +0.0002 & +0.0001 \\
\hline
\end{tabular}

In the above deterninations No. I was among the first made, and it is possible that the slightly high results obtained were due to lack of familiarity with the method. Excluding No. I, the average would be as follows:

$\begin{array}{cccc}\text { KCl used. } & \mathrm{KCl} \text { found. } \\ \text { Gram. } & \text { Gram. } & \begin{array}{c}\text { Error on } \mathrm{KCl} \\ \text { Gram. }\end{array} & \begin{array}{c}\text { Error on } \mathrm{K}_{2} \mathrm{O} . \\ \text { Gram. }\end{array} \\ 0.0647 & 0.0647 & 0.0000 & 0.0000\end{array}$

It would thus appear that the determination of potash as perchlorate in mixtures free from other bases and non-volatile acids, is quite accurate, equally as much as the determination by platinum salt.

After nitrogen and phosphoric acid, potash is the componnd one has mostly to determine in fertilizers, plants, and soils. The potash is usually combined with sulphuric, nitric, or carbonic acid, and more rarely with phosphoric acid. 
These salts are almost always associated with alkaline salts and the alkaline earths. It is now therefore a question of the applicability of the perchloric acid method to the determination of potash when associated with these other bases, and non-volatile acids, such as sulphuric and phosphoric acid. In regard to the bases it has been contended by some that magnesia is a disturbing element in the determination of potash by perchloric acid.

Schloesing has shown, however, that in the following mixture, after the removal of sulphuric acid by barium chloride and conversion of bases into perchlorates, the magnesia did not have any disturbing effect.

\begin{tabular}{|c|c|}
\hline & Gram. \\
\hline Potassium chloride $\ldots \ldots \ldots \ldots \ldots \ldots \ldots$ & 0.0835 \\
\hline 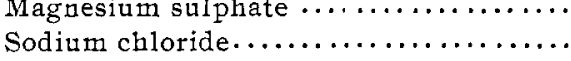 & \\
\hline Calcium chloride $\ldots . \ldots \ldots \ldots \ldots \ldots \ldots$ & $0.233^{\circ}$ \\
\hline
\end{tabular}

In this mixture, there was recovered, by proceeding as above stated, 0.0814 gram potassium chloride. Kreider has also shown that magnesia has no disturbing effect. He treated o.r 500 gram magnesium carbonate with perchloric acid, evaporated till fumes of perchloric acid appeared and cooled, when magnesium perchlorate crystallized; on treating this with alcohol a perfectly clear solution was obtained. It was also thought that it was necessary to remove all non-volatile acids, previous to the separation of the potash as perchlorate. Caspari and Kreider have, however, shown that it is only necessary to remove sulphuric acid. In order to secure a nearly complete separation of phosphoric acid from the potassium, Kreider has shown that a considerable excess of perchloric acid should be left upon the potassium perchlorate before it is treated with the alcohol.

Kreider's results on a mixture containing

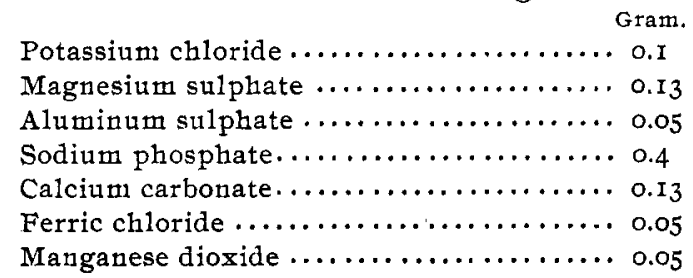

were quite promising as will be seen from the results reported in the American Joumal of Science, 49, 448. 
The method as modified by Caspari and Kreider is quite promising, and I hope in the near future to do some further work on the determination of potassium associated with other bases and non-volatile acids.

\section{Preparation of Perchloric Acid.}

As perchloric acid is not a regular article of commerce it becomes necessary for each one desiring it to make his own supply. There may be mentioned briefly four methods for its preparation and the literature in which detailed directions may be found.

The Method as Proposed by Schloesing.-Prepare first potassium perchlorate from potassium chlorate by heating in the usual way. The mass after the decomposition of the chlorate is treated with boiling water, and then rapidly cooled; the crystals of potassium perchlorate separate; the potassium chloride remains in solution with some of the perchlorate also. The perchlorate is then dissolved and treated with sufficient quantity of hydrofluosilicic acid to obtain the potassium fluosilicate, the perchloric acid being liberated. After standing a while the precipitate is filtered off, and the filtered solution containing the perchloric acid is concentrated and treated with ammonia. The ammonia salt is next decomposed by hydrochloric and nitric acids, and the solution then evaporated on a water-bath to a sirupy consistency.

The solution is left in this condition for a day or two, to separate further any crystals of potassium perchlorate it may contain. The supernatant liquid is then ready for use after a blank experiment has been conducted with the same.

Process of Perrey.-Perrey has sought to avoid completely the presence of potash in the reagent. $\mathrm{He}$ makes use of the principle recognized first by Sèrullas that chloric acid, distilled, furrishes a third of its weight of perchloric acid. Barium chlorate, a salt easily prepared, is dissolved in water, and the solution precipitated with sulphuric acid, leaving the chlorate, however, in slight excess. After filtration the solution is concentrated and distilled, the distillate being collected for use as soon as white vapors show themselves in the body of the retort.

The product which one receives is contaminated with a little chloric acid and chlorine which can be expelled on the waterbath. The yield of perchloric acid is about the same as in the 
Schloesing process. For details of these two processes consult Grandeau: "Traité d' Analyse des Matières agricoles," I, 88-9I.

Caspari's Method.-This method is quite similar in principle to the method descrided by Schloesing. Potassium chlorate is used as a basis, potassium perchlorate being prepared from it in the usual way. The potassium perchlorate dissolved in water is then treated with hydrofluosilicic acid at the boiling temperature, the reaction being as follows:

$$
2 \mathrm{KClO}_{4}+\mathrm{H}_{2} \mathrm{SiF}_{6}=\mathrm{K}_{2} \mathrm{SiF}_{6}+2 \mathrm{HClO}_{4} .
$$

The solution is then filtered on an asbestos filter under pressure, the clear filtrate evaporated on a steam-bath to small bulk, and allowed to stand for twenty.four hours, whereby is effected the separation of any remaining potassium fluosilicate or perchlorate. It is again filtered and diluted with an equal quantity of water and barium chloride added in slight excess to remove last traces of sulphuric acid and hydrofluosilicic acid. The clear supernatant liquid is then poured off and evaporated on a water-bath till white fumes of perchloric acid appear.

The solution is then, after allowing any potassium perchlorate that may be present to separate again, diluted with water and the excess of barium salt most carefully removed with sulphuric acid. The solution is allowed to stand for several days, then filtered throngh paper, and is ready for use.

For details of the process consult Wiley's Agricultural Analysis, 2, 290, and Ztschr. angew. Chem., 1898, p. 68.

Kreider's Method.-By far the most simple and rapid of all the methods proposed for the preparation of perchloric acid is that worked out by Kreider. The method depends upon the production of sodium perchlorate from sodium chlorate by heating, in the usual way, the subsequent decomposition of the sodium perchlorate byhydrochloric acid with the liberation of perchloric acid and the precipitation of sodium chloride which is separated by decantation or filtration. The filtered solution is concentrated on a water-bath till white fumes of perchloric acid appear, then cooled and diluted with water when it is ready for use.

It is manifest that the acid thus prepared is not chemically pure, since sodium chloride is not absolutely insoluble in hydrochloric acid but if a portion of the acid prepared as above be 
tested with silver nitrate it will be readily seen that any sodium chloride which may have remained in solution, has been converted into perchlorate. Furthermore, unless the sodium chlorate used contained some potassium or on evaporation the acid was exposed to fumes of ammonia, the residue from the evaporation of a portion of the acid prepared as above, will be entirely soluble in alcohol, and the presence of any sodium perchlorate is therefore entirely unobjectionable.

I have in the course of my work on this subject prepared the acid by this method several times, and have always found the process very satisfactory, requiring but little time and attention. In my work, however, I found, as the result of blank determination on the acid thus prepared, a very small residue insoluble in alcohol for which in all cases corrections were made. This correction was very slight, and in no way condemns the process, since it is a very simple matter to determine it once for all on any lot of acid, and make the proper use of the same in the actual determination.

For detail of the process consult Kreider's article in the Amcrican Journal of Science, 49, 445-446.

[CONTRIBLTIONS FROM THE CHEMICAL LABORATORY OF THE UNIVERSITY OF IIIINOIS.]

\section{IMPROVED APPARATUS.}

BY J. L, SAMMIS.

Received October 10,1898 .

BURETTE.

THE frequent use of Mohr's burette with Geissler's glass stop-cock during the past summer called the writer's attention to two points which, it was thought, might be improved.

The handle of the glass stop-cock, as usually made, is turned toward the right. Right-handed persons usually find it easier to operate the stop-cock with the left hand and stir or shake the titrated liquid with the right. In order to facilitate this, the stop-cock of a burette was cut off and sealed on again with its handle toward the left. See Fig. I.

In titrating, much care has to be exercised lest the mark upon the float should sink below the graduations on the 